\section{Factors Affecting Pollen Dispersal in High-density Apple Orchards}

\author{
Paul Kron and Brian C. Husband ${ }^{1}$ \\ Department of Botany, University of Guelph, Guelph, Ontario, N1G 2Wl, \\ Canada
}

Peter G. Kevan and Svenja Belaoussoff
DepartmentofEnvironmental Biology, University of Guelph, Guelph, Ontario,
N1G 2 W1, Canada

Additional index words. Malus $\times$ domestica, gene flow, allozymes, cross-compatibility, siring success, pollination, orchard design

\begin{abstract}
Knowledge of pollen dispersal is essential for maximizing cross-fertilization in apples (Malus $\times$ domestica Borkh.) and achieving optimal orchard design. Using allozyme markers, we examined dispersal of pollen from trees of a single cultivar ('Idared') throughout two apple orchards. In each orchard, the percentage of seeds sired by 'Idared' was estimated for trees sampled at regular intervals along three transects, extending up to 18 rows $(86 \mathrm{~m})$ from the closest donor trees. The percentage of seed sired by 'Idared' pollen ranged from $76 \%$ to $1 \%$ of seed sampled for a row. No differences in pollen dispersal were found among transects, despite differences in proximity to the bee colonies. Variation in 'Idared' siring success was attributable to the cultivar of the fruit-bearing trees as well as their distance to the nearest 'Idared' tree. Cultivar effects were associated with differences in flowering overlap, but not cross-compatibility with the pollenizer. Furthermore, flowering overlap was a good predictor of siring success only when the flowering times of competing pollenizer cultivars were also considered. The implications for orchard design are discussed.
\end{abstract}

Pollen dispersal is an inconspicuous process, yet it is critical to the ecology and genetics of wild and domesticated plants. Through the transmission of genes, pollen dispersal influences the degree of inbreeding and the organization of genetic diversity within and between populations (Wright, 1978), and represents a selective agent governing the evolution of plant floral form and life history (Charlesworth and Charlesworth, 1981; Charnov, 1982; Harder and Thomson, 1989; Willson, 1979). Knowledge of pollen dispersal also has practical significance, as it is essential for crop production and optimal orchard design, in which the goal is to manage patterns of mating within and among crop cultivars. Despite its significance to fundamental and applied research, patterns of pollen movement historically have been difficult to quantify and thus the magnitude of pollen dispersal and its

Received for publication 3 Nov. 2000. Accepted for publication 22 Mar. 2001. We thank Jack Van Diepen and Bill Derks for access to their orchards, Sue Hall, Terri Feltz, Alison Skinner, Mark Robinson, and Bob Baliger for field assistance; John Gardner for assistance in the development and field component of the study; and the Ontario Ministry of Agriculture, Food and Rural Affairs, Ontario Apple Marketing Commission and Ontario Beekeepers Association for financial support. The cost of publishing this paper was defrayed in part by the payment of page charges. Under postal regulations, this paper therefore must be hereby marked advertisement solely to indicate this fact.

${ }^{1}$ To whom reprint requests should be addressed. Phone: (519) 824-4120 ext. 4790; Fax: (519) 7671991; E-mail: bhusband@uoguelph.ca ecological determinants still are poorly understood.

Pollen dispersal and siring success have special significance in commercial apple orchards. Apples are self-incompatible and, hence, fruit production occurs only with pollen transfer between cultivars (Free, 1993). To complicate matters, most orchards consist of a limited number of cultivars, which are arranged in monotypic blocks or rows. The potential for pollen wastage through pollination between trees of the same cultivar and the resulting economic costs due to lost fruit yield or quality highlights the need to predict accurately patterns of pollen movement in orchards. Pollen dispersal in apples has received considerable attention; however, most studies are based on apparent rather than realized pollen dispersal (Free, 1962; Free and Spencer-Booth, 1964; Wertheim, 1991), and there have been few attempts to relate factors other than distance to pollination success. Furthermore, few studies have been conducted on more contemporary high-density orchards. In these orchards, apples are grown on dwarf rootstock for early yields and low shading, but the rows are cultivated at such high densities that pollinators may be more likely to move along rows than across, which is necessary for successful pollination (Dale et al., 1992; Free, 1993; Kron et al., 2001; Mayer et al., 1986).

In this study, we examined pollen dispersal in two apple orchards by tracking the movement of cultivar-specific allozymes using paternity analysis. We focused on a single apple cultivar ('Idared'), whose paternity could be tracked unambiguously in all cultivars within a large area of each orchard. By screening for its unique alleles in seeds, we estimated its siring success on trees throughout the orchard. The following questions were of primary interest: what proportion of the seeds sampled were sired by the targeted pollenizer cultivar; to what extent is variation in siring success attributable to distance vs. the identity of the recipient cultivar; and are differences in siring success on different recipient cultivars related to overlap in flowering phenology and crosscompatibility with the pollen donor?

\section{Materials and Methods}

The field research was conducted in 1998 and 1999 in two commercial apple orchards, Farmer Jack's Orchard and Dwarf Tree Orchard, near London, Ontario, Canada. Both orchards contain trees grafted on dwarf rootstock (Malling 9 and Malling 26), and are planted at densities near or exceeding 900 trees/ha (Farmer Jack's, 1170 trees/ha; Dwarf Tree, 883 trees/ha). These densities are considered high density for Malling 26 and medium to high density for Malling 9 (Wilson, 1990). In both orchards, trees were organized into rows with a road running perpendicular to the rows through the center of the orchard (Fig. 1). Farmer Jack's Orchard consists of $\approx 30,000$ trees and 16 cultivars; Dwarf Tree Orchard has $\approx 12,000$ trees and 14 cultivars. Both orchards contain some pear trees, and Farmer Jack's has a variety of other fruit crops located within the orchard. In both orchards, hives were placed along the main road during the bloom period at a density of 0.5 to 1 hive/ha.

Sampling for gene flow. Through a preliminary allozyme screening, we identified 'Idared' as a genotype (cultivar) that could readily be identified in a paternity analysis of seeds. An isolated row or block of 'Idared' trees was then located in each orchard. At Farmer Jack's Orchard, the three-row block selected was the nearest source of 'Idared' pollen for 21 rows in the direction sampled, and at Dwarf Tree Orchard, the four-row block selected was the nearest 'Idared' pollen source for 15 rows in the sampling direction. On 27 Aug. 1998, ripe apples were collected from trees in the 'Idared' row and from nine neighboring rows (containing 'McIntosh', 'Mutsu', 'Delicious', 'Northern Spy', and 'Empire'). These nine rows were spaced 1, 2, 3, 5, 7, 9, 12,15 , and 18 rows in one direction away from the 'Idared's. The average distance between rows was $4.75 \mathrm{~m}$ at Farmer Jack's Orchard and $4.9 \mathrm{~m}$ at Dwarf Tree Orchard. Trees were sampled along three transects running perpendicular to the rows and parallel to the central road (Fig. 1). One transect consisted of the second tree away from the road, where bee colonies were located, and the other two transects in each orchard were at randomly selected distances from the road.

To sample the apples, the circumference of each tree canopy was roughly divided into four quarters and a low, a middle, and a high branch were selected in each quarter. One apple was selected from each branch by assigning a number to each apple based on its 


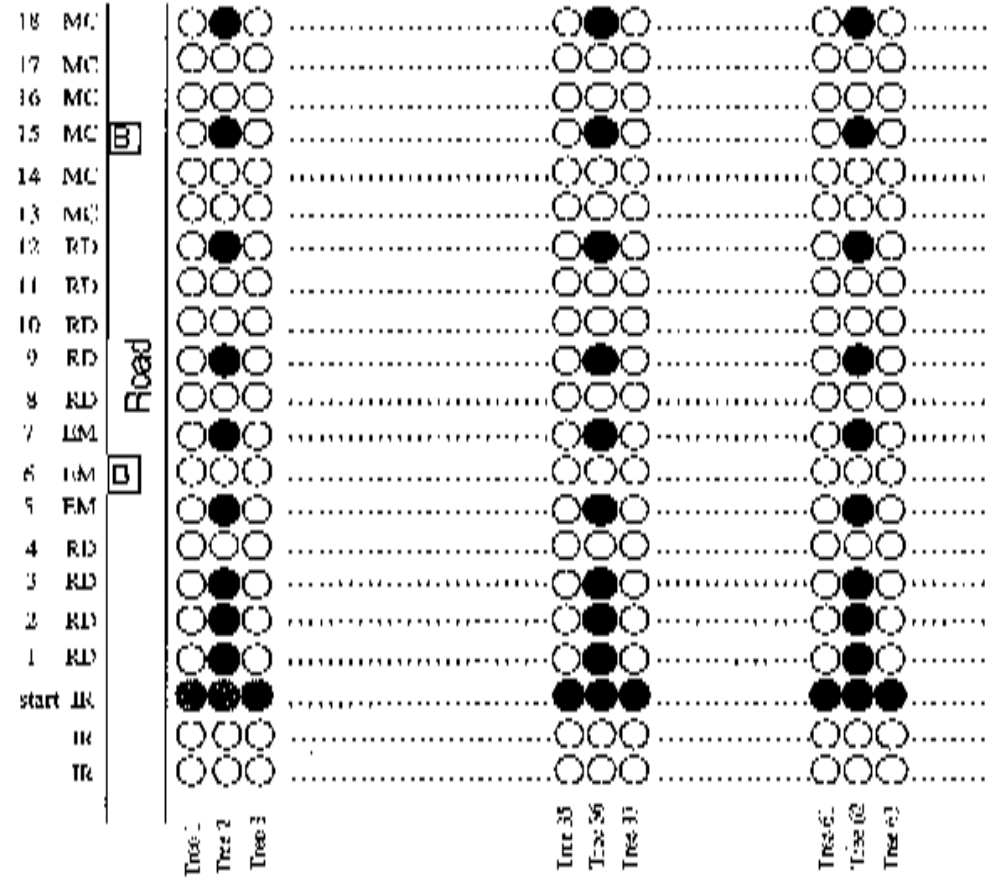

\section{A: Farmer Jack's}

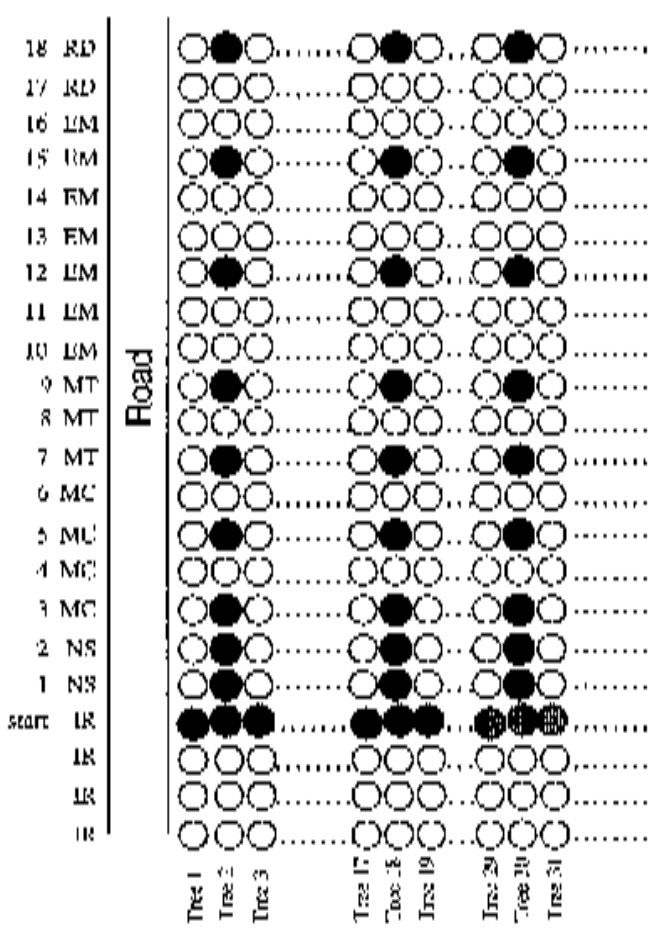

\section{B: Dwarf Tree}

Fig. 1. Map of the sampling area in (A) Farmer Jack's Orchard and (B) Dwarf Tree Orchard, Ontario, Canada. Each diagram indicates the cultivars present $(\mathrm{MC}=$ 'McIntosh', $\mathrm{RD}=$ 'Delicious', $\mathrm{EM}=$ 'Empire', IR $=$ 'Idared', MT = 'Mutsu', NS = 'Northern Spy'), by row, the location of the transects (black circles) from which trees were sampled, and the position of the central road along which the beehives were located in both orchards. Hive positions ('B') are shown at Farmer Jack's; hives were spaced approximately every eleven rows at Dwarf Tree Orchard, but exact locations are not known. Dots indicate additional trees not shown. position on the branch, obtaining a random number, and selecting the apple of that number. Where insufficient numbers of apples were available to follow this protocol, either at the tree, quarter, or branch level, an apple was selected randomly from those available. In total, 12 apples were selected from each tree. Apples were refrigerated intact until seeds were extracted for electrophoresis.

Electrophoresis. At least 30 seeds, sampled as evenly as possible across all collected apples, were extracted for each tree and their allozyme profiles scored using cellulose acetate electrophoresis. For each seed, the seed coat was removed and the embryo and cotyledons were ground in $50 \mu \mathrm{L}$ of "Decodon" extraction buffer (Eckert and Barrett, 1994) after freezing in liquid nitrogen. The homogenate was centrifuged for 8 to $12 \mathrm{~min}$ in a refrigerator and the supernatant was applied to cellulose acetate gels.

Gels were run for 45 to $60 \mathrm{~min}$ at $250 \mathrm{~V}$ and stained for four enzymes. The enzymes 6-phosphogluconate dehydrogenase (6PGD, EC 1.1.1.44), aspartate aminotransferase (AAT, EC 2.6.1.1), and acid phosphatase $(\alpha A C P, E C$ 3.1.3.2) were resolved on a morpholine-citrate ( $\mathrm{pH}$ 6.5) buffer system, while phosphoglucomutase (PGM,EC 2.7.5.1) was resolved on a tris-citrate $(\mathrm{pH} 7.0)$ buffer system (Hebert and Beaton, 1989; Manchenko, 1994). Four polymorphic loci were scored (Table 1): 6Pgd-1 comprised four alleles (a,b,c,d; a is most anodal); Aat-4 and Pgm-5 consisted of two alleles each, and these were designated "f" (fast) or "s" (slow) based on their relative mobilities. The $\alpha A c p-1$ locus was scored for the presence or absence of a band labeled "f", where absence was designated as "n" (null). Scoring of 6Pgd-1 and $P g m-5$ was based on Weeden and Lamb (1985, 1987).

Identification of 'Idared' parentage. The 'Idared' genotype was homozygous for the "s" allele of Aat-4 and for the "f" allele of $\alpha A c p-1$, and is unique among the cultivars in the two orchards in having both these alleles (Table 1). This fact, in combination with information about two other loci $(P g m-5$ and $6 P g d-1)$, allows crosses between 'Idared' and four of the five sampled cultivars ('Delicious', 'McIntosh', 'Northern Spy', and 'Empire') to be uniquely identified. In 'Mutsu' seeds, 'Idared' $\mathrm{x}$ 'Mutsu' crosses can be identified using these same four loci in almost all cases. However, one possible 'Idared' $x$ 'Mutsu' multi-locus genotype $(6 P g d-1=\mathrm{dd}$, Aat $-4=\mathrm{fs}$, $P g m-5=$ fs, $\alpha A c p-1=\mathrm{nf})$, which is expected to occur at a frequency of $22.2 \%$ in such crosses (assuming normal segregation and diploid seeds), also occurs in 'Paulared' $x$ 'Mutsu' crosses. To assess the likelihood that seeds of this genotype were in fact from 'Idared' $x$ 'Mutsu' crosses, the observed frequency of such seed genotypes was compared to its expected occurrence under strictly 'Idared' $x$ 'Mutsu' mating using a Chi-Square test.

Magnitude of gene flow. The percentage of seeds sired by 'Idared' was calculated for each of the 27 maternal trees sampled in each orchard, and an analysis of variance was used to 
Table 1. Four-locus genotypes of apple cultivars used in the across-row gene flow study. 'Paulared' and 'Vista Bella' are included, because they are the only other cultivars present in either orchard with an $\alpha \mathrm{ACP}-1$ " $\mathrm{f}$ " allele. 'Mutsu' is a triploid.

\begin{tabular}{lcccc}
\hline Cultivar & 6Pgd-1 & Aat-4 & Pgm-5 & $\alpha$ Acp-1 \\
\hline Idared & bd & ss & ff & ff \\
McIntosh & ab & ff & fs & nn \\
Empire & bc & ff & fs & nn \\
Delicious & ac & ff & fs & nn \\
Northern Spy & bb & fs & ss & nn \\
Mutsu & ddd & ffs & fss & nnn \\
Paulared & ad & ff & ss & nf \\
Vista Bella & aa & ff & fs & ff \\
\hline
\end{tabular}

test for differences among rows. For each row, the observed mean percentage of seeds sired by 'Idared' was also expressed as a proportion of all the 'Idared' sired seed observed over all sampled rows.

Sampling for flowering phenology. We examined the overlap in flowering phenology among cultivars because of the potential for such overlap to affect opportunities for crosspollination, and therefore, to affect realized pollen dispersal from one cultivar to another. Flowering phenology data were collected at Farmer Jack's Orchard for 14 cultivars: Vista Bella, Golden Russet, Paulared, Idared, McIntosh, Spartan, Cortland, Empire, Mutsu, Jonagold, Delicious, Granny Smith, Gala, and Northern Spy. These cultivars were chosen because they occur within the paternity sampling areas or in the vicinity, and thus may compete with 'Idared' for pollination opportunities. For most cultivars, 10 trees were marked at regular intervals along the entire length of a randomly selected row. For three cultivars (Idared, McIntosh, and Empire), five trees were selected in each of two different rows. Only eight 'Granny Smith' and two 'Golden Russet' were marked.

On each tree, prior to flowering, three branches were randomly selected and a segment comprising the last five to seven flower trusses closest to the tip was marked. Beginning on 5 May 1999, trees were checked at least every second day and the total number of flowers open in the marked section of each branch was counted. Counting ended on 19 May when the number of open flowers on all cultivars had dropped below $10 \%$ of the cultivar maximum.

Analysis. For each cultivar, a cumulative percent flowering curve was generated as follows: for each sampling day, the number of flower-days to date (open flowers per day summed across days since the first census) was expressed as a percentage of the total flower-days for the cultivar over the entire period of observation (open flowers per day summed for all days). The shapes of these flowering curves were then compared using the Kolmogorov-Smirnov test (Sokal and Rohlf, 1981). All 91 possible pairwise comparisons between cultivars were tested, with the sequential Bonferroni technique (Holms, 1979 as cited in Rice, 1989) used to correct for multiple comparisons.

The overlap in flowering between 'Idared' and other cultivars was described in three ways: 1) days between peak flowering; 2) percentage of overlap with 'Idared'; and 3) weighted overlap with 'Idared', each of which is described below.

The number of days between peak flowering in two cultivars has been used previously to evaluate the suitability of pairing two cultivars for cross-pollination (e.g., Lateur, 1996; Wertheim, 1996). We therefore identified the day on which the number of open flowers reached its maximum for each cultivar, where number of open flowers was the average across all trees for that cultivar. Because trees were not monitored every day, this observed peak was $\pm 1 \mathrm{~d}$ of the actual peak for some cultivars.

Percentage of overlap in flowering between 'Idared' and other cultivars was also estimated. Each day, the number of flowers open for a cultivar (all trees combined) was counted. The number open on each day was then expressed as a percentage of the total flower-days for that cultivar, so that the daily measures would total to one if summed over all days. Each daily measure was then compared with the 'Idared' measure for that day, and the lower of the two values was taken as the daily measure of overlap with 'Idared'. The daily overlap values were then summed to generate a single measure of the overlap between the cultivar and 'Idared', potentially ranging from 0 (no overlap) to 1 (complete overlap).

The measure above describes the relative overlap of flowering between two cultivars. In an orchard, however, the proportion of pollen contributed by one pollenizer cultivar to a pollen-recipient cultivar may also depend on the pollenizer's relative abundance and on the overlap in flowering between the recipient cultivar and all other cultivars within pollen dispersal range (referred to here as the pollination neighborhood). For these reasons, we generated a weighted measure of flowering overlap between each row of a recipient cultivar and 'Idared', which took into account the proportion of 'Idared' trees in a 40-row neighborhood around the recipient cultivar row and the cultivar composition of the neighborhood, including the presence of additional rows of the recipient cultivar (which would not be compatible pollen donors). This measure was therefore applied at a row-by-row, rather than cultivar-by-cultivar, level.

First, we estimated the proportion of 'Idared' pollen in the pollen pool available to a given recipient row on a given day. An area comprised of twenty rows on either side of the recipient row was used as an arbitrary neighborhood size exceeding the observed maximum distance of gene flow (18 rows at Farmer Jack's Orchard; see Results). For the 'Idared' pollenizer and each cultivar in the 40-row neighborhood, daily flowering measures were generated as described above (percentage of total number of flower-days for the cultivar). These measures were then weighted for each cultivar by multiplying them by the proportional representation of the cultivar in the 40row neighborhood (i.e. the number of rows of the cultivar in question, divided by the total number of rows of potential pollen donors in the neighborhood; potential pollen donors are all cultivars other than the recipient-row cultivar). The proportional 'Idared' representation in the pollen pool each day was determined by dividing the 'Idared' measure by the sum of weighted measures for all cultivars in the 40-row neighborhood for that day.

To determine the weighted overlap between "Idared' and a row of a recipient cultivar on a given day, the proportional representation of "Idared" for that day, as described above, was multiplied by the unweighted daily flowering measure of the recipient cultivar. This product was calculated for each recipient row on each day, and the sum of these products across all days was calculated as the weighted phenological overlap between 'Idared' and the recipient trees in that row. This measure equals 1 if all of the potential pollen donors in the neighborhood are 'Idared' trees; it measures 0 if no 'Idared' trees are present, or if the recipient row flowering does not overlap with 'Idared' at all.

When this value was calculated at Dwarf Tree Orchard, two cultivars were present for which there were no flowering phenology data. These cultivars were assigned the average daily flowering values of all other cultivars present in the neighborhood for the purposes of calculation.

Cross-compatibility pollination treatments. We examined cross-compatibility among cultivars because differences in cross-compatibility may affect the proportion of deposited pollen that ultimately fertilizes ovules in different crosses, and therefore, may affect realized pollen dispersal from one cultivar to another. Between 10 May and 14 May 1999 at Farmer Jack's Orchard, 'Idared' trees were crossed with flowers on ten trees each of five cultivars: 'McIntosh', 'Mutsu', 'Empire', 'Delicious', and 'Northern Spy'.

One branch was chosen on each tree and marked below the fifth truss. All but two flowers per truss were removed (king blossom always removed) so the results of the hand pollinations were not affected by resource limitation. The branch was then covered with a pollination bag before any flowers had opened. Flowers on four of the trusses were emasculated, then pollinated with 'Idared' pollen, using anthers collected the same day. In the fifth truss, flowers were self-pollinated by hand.

Hand-pollinated flowers were censused four times during the summer (26 May, 10 


\section{A Farmer Jack's}

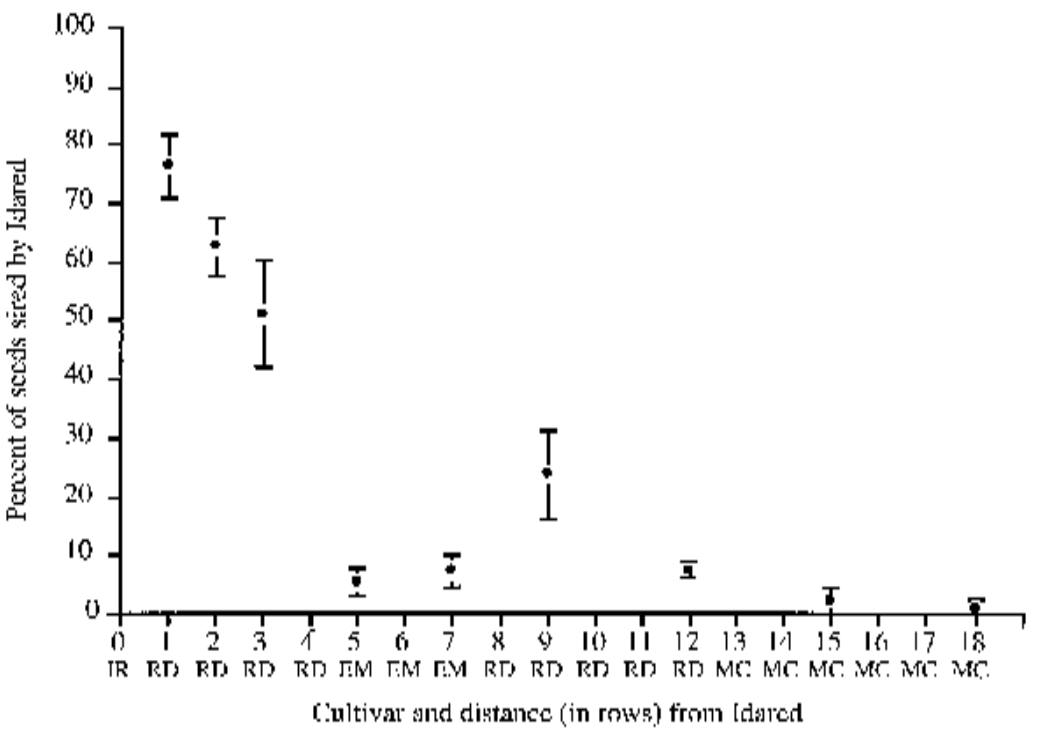

\section{B Dwarf Tree}

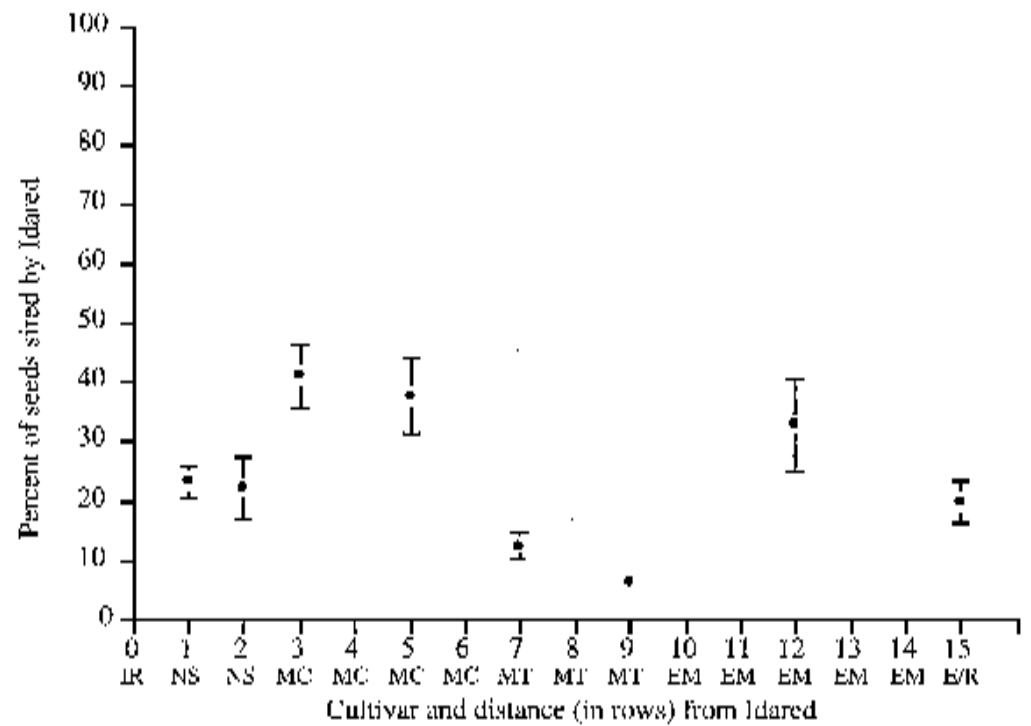

Fig. 2. Pollen-mediated gene flow, measured as mean (SE) percentage of seeds sired by the 'Idared' genotype, at increasing distances (rows) from the nearest row of 'Idared'. (A) Farmer Jack's Orchard. (B) Dwarf Tree Orchard. Cultivar is given for each row $(\mathrm{MC}=$ 'McIntosh', $\mathrm{RD}=$ 'Delicious', EM = 'Empire', IR = 'Idared', $\mathrm{MT}=$ 'Mutsu', NS = 'Northern Spy', E/R = 'Empire' and 'Delicious' rows pooled as they were equidistant from the nearest 'Idared' row.

June, 30 June, and 23 July). The first census was prior to chemical thinning in the orchards, which began 28 May. On each occasion, the number of fruit remaining on the treated branches was determined. All fruit were collected on either 26 Aug. or 2 Sept. At this time, apples were opened and their seeds counted. Because both orchards received an application of chemical thinner, the fruit and seed production values will reflect not only the genetic compatibility of each pair of cultivars but also any other factors in a working orchard that may influence fruit development.

Fruit set and seed production. Fruit set was calculated as the number of fruit observed on a treatment branch divided by the number of flowers pollinated on that branch. This value was then averaged across trees for that cultivar to get a cultivar mean fruit set value.

For each tree that produced fruit from at least one treated flower, the mean number of seeds per fruit was calculated. A cultivar mean value for seed number per fruit was obtained by averaging these values across all fruitproducing trees of that cultivar. In addition, for each tree, the average seed number per treated flower was calculated by multiplying that tree's fruit set value by its average seed number per fruit. These values were then averaged across all trees of a given cultivar to obtain a cultivar mean value. For each of these measures, differences among cultivars were tested using an analysis of variance, with a Tukey-Kramer HSD test used to test for pairwise differences between cultivars.
Factors affecting pollen-siring success. For Farmer Jack's Orchard, the effects of maternal cultivar and distance from the nearest 'Idared' row on the percentage of 'Idared'-sired seeds were tested using an analysis of covariance, after testing for homogeneity of regression slopes. The percentage of 'Idared' seeds was arc-sin transformed for this and following analyses. For Dwarf Tree Orchard, it was not possible to test for homogeneity of regression slopes, because no cultivar occurred at more than two distances from the 'Idared' row. Instead, the effect of maternal cultivar was examined using an analysis of variance (ANOVA), and the effect of distance was examined separately using a linear regression analysis.

The effect of maternal cultivar was examined further by replacing the cultivar variable with one cultivar-specific variable (cross-compatibility with 'Idared') and one row specific variable (weighted flowering overlap with 'Idared'), and the effects of these two factors, in combination with minimum distance to 'Idared', were evaluated using a multiple regression analysis. For this analysis, cross-compatibility was expressed in terms of fruit set, to be consistent with the protocols of Wertheim (1996).

Prior to performing multiple regression analyses, we tested for multi-collinearity by examining pair-wise correlations between the independent variables, using the criterion that pair-wise correlations are of concern if $|r|>0.7$ (Gunst and Mason, 1980).

\section{Results}

Flowering phenology. Apple bloom began on 5 May 1999. At that time, only two cultivars had started flowering ('Golden Russet' and 'Idared'). Five of the remaining 12 cultivars had flowers open on 6 May, and the remainder started flowering on 7 or 8 May. By the last census day (19 May), all cultivars still had a small number of open flowers except for 'Spartan', 'Golden Russet', and 'Jonagold'. Flowering curves are shown for the six cultivars used in the gene flow component of this study (Fig. 3).

The 14 cultivars censused fell into five groups defined by the day of peak flowering (Table 2). The maximum number of days between peak flowering for any two cultivars was $8 \mathrm{~d}$ (between Group one and Group five cultivars). The maximum difference between 'Idared' and any of the cultivars included in the across row analyses was $4 \mathrm{~d}$ (for 'Delicious' and 'Northern Spy').

From the pair-wise comparisons of flowering phenology we found significant differences between all possible cultivars [Kolmogorov Smirnov Test: $P<0.05$; critical $P \leq$ 0.0125 was required for table-wide significance of $\alpha=0.05$, sequential Bonferroni test (Holms, 1979)], with four exceptions; 'Empire' vs. 'McIntosh' $\left(D=0.029, D_{\mathrm{c}}=0.037, P=0.21\right)$, 'Mutsu' vs. 'Spartan' $\left(D=0.045, D_{\mathrm{c}}=0.040\right.$, $P=0.016)$, 'Spartan' vs. 'Jonagold' ( $D=$ 0.046, $D_{\mathrm{c}}=0.039, P=0.013$ ), 'Empire' vs. 'Cortland' $\left(D=0.044, D_{\mathrm{c}}=0.038, P=0.014\right)$.

Measures of percentage of flowering overlap with 'Idared' varied from a low of 0.47 for 


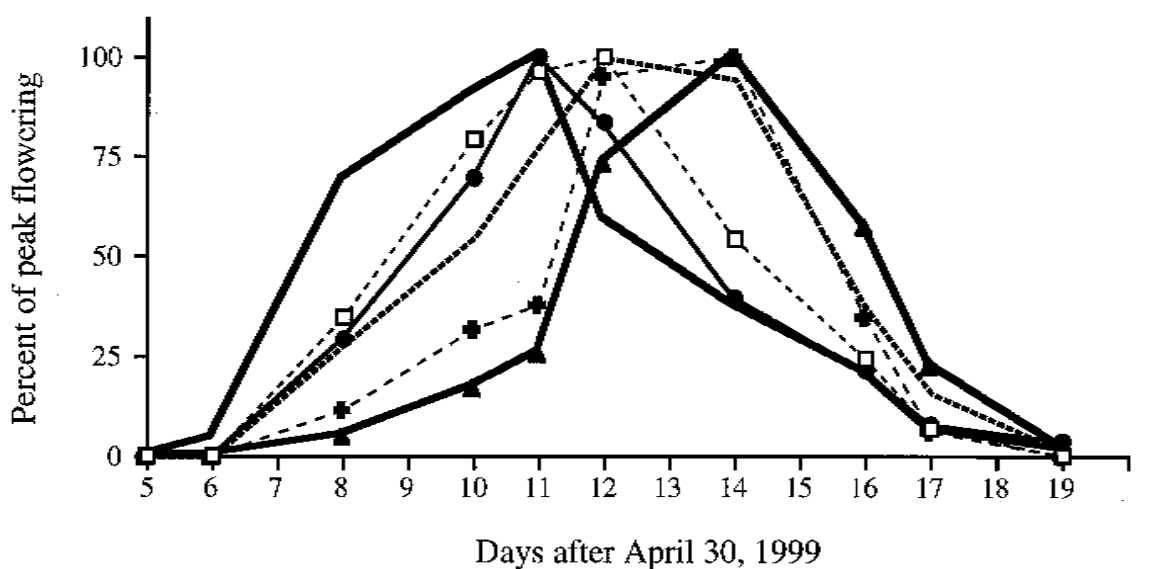

Fig. 3. Timing of flowering as percentage of maximum bloom number for six apple cultivars censused in Farmer Jack's Orchard in 1999. 'Idared' $=\square$; 'Empire' = - $\quad$ - ;'Mcintosh' 'Mutsu' = - - - ; 'Delicious' = - + - ; Northern Spy' = $\mathbf{L}$.

Table 2. Apple cultivars in the Farmer Jack's Orchard and Dwarf Tree Orchard classified by day of peak flowering. Underlined cultivars were included in the across-row gene flow analyses.

\begin{tabular}{lcc}
\hline \hline Group & Cultivars & Day of peak flowering \\
\hline 1 & Vista Bella & 7 May to 9 May \\
2 & Golden Russet and Paulared & 9 or 10 May \\
3 & $\underline{\text { Idared and McIntosh }}$ & 11 May \\
4 & Spartan, Cortland, Empire, and Mutsu & 12 or 13 May \\
5 & Jonagold, Delicious, Granny Smith, Gala, and Northern Spy & 13 to 15 May \\
\hline
\end{tabular}

'Gala' to a high of 0.87 for 'Paulared', where 0 is no overlap and 1 is complete overlap (Table 3). Among the cultivars included in the across row pollen movement analyses, values for overlap with 'Idared' ranged from 0.48 ('Northern Spy') to 0.86 ('McIntosh'). Measures of weighted flowering overlap between sampled rows and 'Idared' ranged from 0.082 for row seven to 0.14 for row 18 at Farmer Jack's Orchard, and from 0.075 in row two to 0.27 in row 15 at Dwarf Tree Orchard (Fig. 4).

Cross-compatibility. There were significant differences among cultivars for cross-compatibility with 'Idared', measured in terms of fruit set $\left(F_{4,45}=7.51, P=0.0001\right.$; Table 4$)$, seed number per fruit $\left(F_{4,26}=25.43, P<0.0001\right.$; Table 4), and seed number per flower (fruit set $\times$ seed number per fruit) $\left(F_{4,45}=9.75\right.$, $P<0.0001$; Table 4).

Pollen-mediated gene flow. In 'Empire', 'Delicious', 'Northern Spy', and 'McIntosh', all seeds sired by 'Idared' could be identified unambiguously. Of the 18 seeds from 'Mutsu' trees identified as being potentially sired by 'Idared' pollen, 14 could be attributed to 'Idared' conclusively, while 4 were either of 'Idared' or 'Paulared' parentage. These four seeds were assumed to be sired by 'Idared' in all of the results presented below, for two reasons. First, the minimum distance to an 'Idared' row was nine rows or less, while the minimum distance to a 'Paulared' row was 34 or more rows, making 'Idared' the more likely parent of the two. Second, the observed number of seeds with the uncertain genotype (four) was not significantly different from the expected number of that genotype, if one assumes that all seeds in question were sired by
'Idared' (Chi-square Test, $\chi^{2}=2.75, P=$ 0.097).

The proportion of seeds sired by 'Idared' varied significantly across rows at Farmer Jack's Orchard $\left(F_{8,18}=31.12, P<0.0001\right.$; ANOVA $)$ and at Dwarf Tree Orchard $\left(F_{8,18}=\right.$ $7.74, P=0.0002$; ANOVA). At Farmer Jack's Orchard, the mean percentage of seeds sired by 'Idared' ranged from $76 \%$ in row one (a 'Delicious' row) to $1 \%$ in row 18 (a 'McIntosh' row) (Fig. 2A), and the highest values were those closest to the 'Idared' rows. Eighty percent of all observed seeds fertilized by 'Idared' were found in the first three rows, and the average distance from the 'Idared' block was $15.8 \mathrm{~m}$. At Dwarf Tree Orchard, the highest percentage of seed sired by 'Idared' was in row three (42\%; a 'McIntosh' row) and the lowest was in row nine $(6 \%$; a 'Mutsu' row) (Fig. 2B). The first three rows (closest to the 'Idared's) accounted for $44 \%$ of all observed seeds fertilized by 'Idared', and the $80 \%$ level was not reached until after row nine. In this orchard, the average distance from the nearest 'Idared' block was $30.4 \mathrm{~m}$.

The realized pollen dispersal curves did not differ among transects within Farmer Jack's Orchard (Kolmogorov-Smirnov test: trsct 1 vs. $2, D=0.05$; trsct 1 vs. $3, D=0.07$; trsct 2 vs. $3, D=0.11$; critical value of $D>0.21$ for all comparisons, $P>0.70$ for all comparisons) or Dwarf Tree Orchard (Kolmogorov-Smirnov test: trsct 1 vs. $2, D=0.19$; trsct 1 vs. $3, D=0.07$; trsct 2 vs. $3, D=0.17$; critical value of $D>0.21$ for all comparisons, $P>0.15$ for all comparisons).

Factors affecting pollen-siring success. We used an analysis of covariance to assess the effects of cultivar and distance on the percent-
Table 3. Percentage of flowering overlap between each of 14 apple cultivars and the pollen donor cultivar, 'Idared'. Underlined cultivars were included in the across-row gene flow analyses.

\begin{tabular}{lc}
\hline Cultivar & Overlap (\%) \\
\hline Paulared & 0.868 \\
Golden Russet & 0.860 \\
McIntosh & $\underline{0.856}$ \\
\hline Empire & $\underline{0.848}$ \\
Vista Bella & 0.827 \\
Cortland & 0.806 \\
Jonagold & 0.762 \\
Mutsu & $\underline{0.713}$ \\
Spartan & 0.712 \\
Granny Smith & 0.581 \\
Delicious & $\underline{0.575}$ \\
Northern Spy & $\underline{0.480}$ \\
Gala & 0.469 \\
\hline
\end{tabular}

age of seed sired by 'Idared' within the sampling area. At Farmer Jack's Orchard, cultivar had a significant effect on the percentage of 'Idared'-sired seeds $\left(F_{2,23}=27.4, P<0.0001\right)$ as did distance $\left(F_{1,23}=73.05, P<0.0001\right)$. Back-transformed least-square means of percent 'Idared'-sired seeds ranged from a low of $1.4 \%$ for 'Empire' to a high of $59.5 \%$ for 'McIntosh'.

At Dwarf Tree Orchard, cultivar had a significant effect on the percentage of 'Idared' sired seeds $\left(F_{4,22}=14.90, P<0.0001 ;\right.$ ANOVA $)$ but distance did not $\left(F_{1,25}=1.46, P=0.24\right.$; linear regression). Cultivar means ranged from a low of $8.9 \%$ for 'Mutsu' to a high of $39.2 \%$ for 'McIntosh', but note that these values do not reflect any correction for distance.

To expand our analysis, we conducted a multiple-regression using two biological attributes (cross-compatibility, weighted flowering overlap) and distance as the independent variables. At Dwarf Tree Orchard, distance was significantly and negatively related $\left(F_{1,23}\right.$ $=5.3, P=0.03$ ) while weighted phenological overlap was positively related $\left(F_{1,23}=29.4\right.$, $P<0.0001$ ) to the percentage of seeds sired by 'Idared'. Cross-compatibility with 'Idared' had no effect on siring success $\left(F_{1,23}=0.11, P=\right.$ 0.75). At Farmer Jack's Orchard, distance and cross-compatibility were both negatively related to the percentage of seeds sired by 'Idared' (distance: $F_{123}=28.02, P<0.0001$; crosscompatibility: $\left.F_{1,23}=18.6, P=0.0003\right)$, whereas weighted phenological overlap was positively related $\left(F_{1,23}=45.8, P<0.0001\right)$.

At Dwarf Tree Orchard, the correlations among the independent variables ranged from $r=0.79$ to -0.95 , and at Farmer Jack's Orchard, the correlations among independent variables ranged from $r=0.48$ to 0.72 . Because of concerns with the collinearity among independent variables when the two orchards were treated separately, with five of six correlations exceeding the 0.7 criterion (Gunst and Mason, 1980), data from the two orchards were pooled and orchard was added as an additional independent variable. Following pooling, the $|r|$ values for pair-wise correlations ranged from 0.0067 to 0.54 .

When we used the weighted measure of phenological overlap, minimum distance to 


\section{A Farmer Jack's}

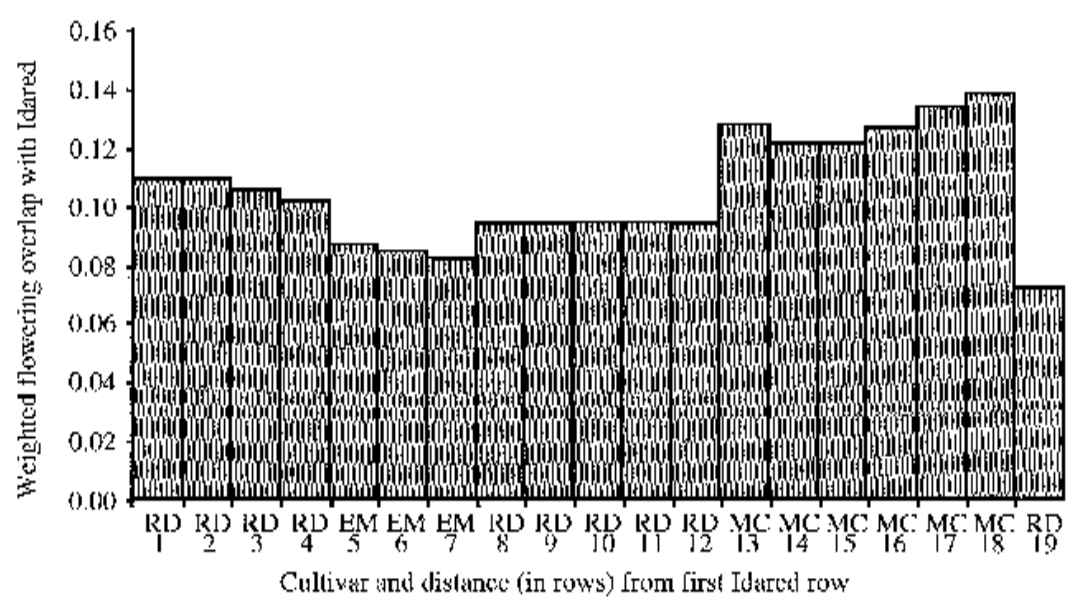

\section{B Dwarf Tree}

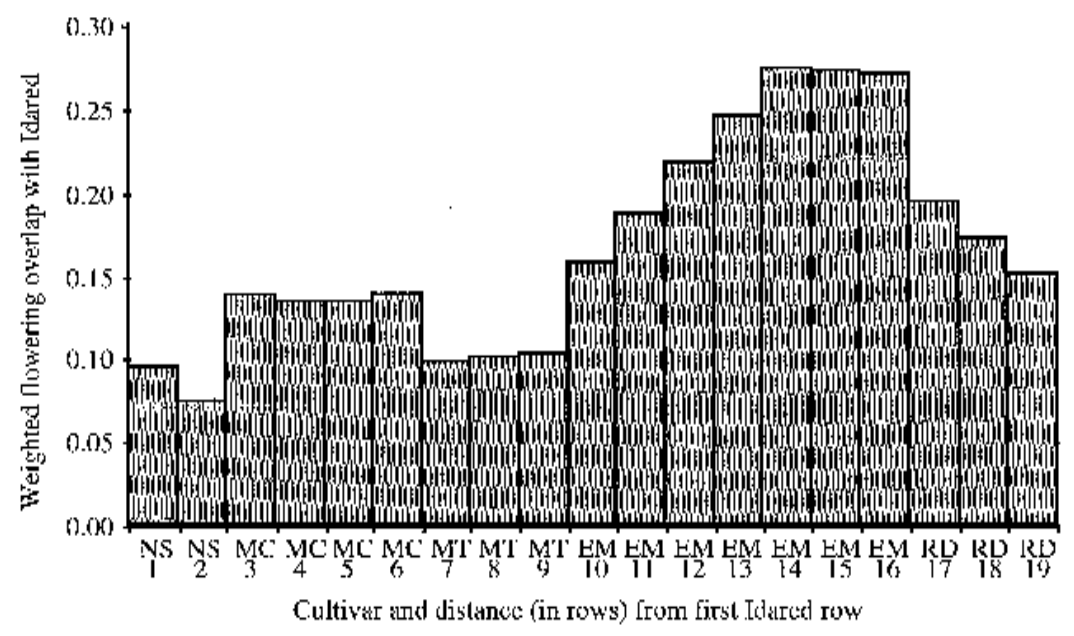

Fig. 4. Weighted flowering overlap values for each row in the sampling area of (A) Farmer Jack's Orchard and (B) Dwarf Tree Orchard. Weighted overlap incorporates the overlap in flowering times between the pollen donor ('Idared') and the recipient (cultivar in the row), weighted by the overlap with other potential donors within 20 rows of the recipient row (See Methods).

'Idared' was negatively correlated $\left(F_{1,49}=\right.$ 105.6, $P<0.0001)$ and weighted flowering overlap was positively correlated with the proportion of 'Idared'-sired seeds $\left(F_{1,49}=37.7\right.$, $P<0.0001$ ) (Table 5). The effect of orchard was nonsignificant $\left(F_{1,49}=3.45, P=0.069\right)$, and cross-compatibility did not explain a significant proportion of variation in 'Idared'sired seeds $\left(F_{1,49}=3.43, P=0.07\right)$. Interestingly, phenological overlap did not explain a significant portion of the variation in pollen siring success when the analysis was repeated with percentage overlap rather than the weighted measure used $\left(F_{1,49}=0.16, P=0.69\right)$.

\section{Discussion}

This study describes the patterns of pollen dispersal from a single pollenizer cultivar ('Idared') throughout an 18-row area consisting of several pollen recipient cultivars. To our knowledge, this study represents the first
Kerster, 1974). In our study, pollen dispersed at least 15 rows $(73.5 \mathrm{~m})$ at Dwarf Tree Orchard and 18 rows $(86 \mathrm{~m})$ at Farmer Jack's Orchard, but $44 \%$ to $80 \%$ of all dispersal occurred within three rows $(\approx 14.5 \mathrm{~m})$ of the pollen donor (Fig. 2). Moreover, realized pollen dispersal generally declined with distance, with over $50 \%$ of the total seed sired in the first four adjacent rows; however, the dispersal distances were irregular and not consistently skewed as expected (Dwarf Tree Orchard in particular).

Similar patterns of pollen dispersal have been estimated for apple orchards previously, based on patterns of fruit set in monotypic blocks and, more recently, using morphological markers (Free, 1962; Free and SpencerBooth, 1964; Maggs et al., 1971; Milutinovic et al., 1995; Wertheim, 1991). For example, Milutinovic et al. (1995) examined fruit set in monotypic blocks of three apple cultivars, which were grown on wild rootstock and received no supplemental pollination. They found that fruit set had occurred up to $35-80 \mathrm{~m}$ from the nearest pollen donor, depending on the cultivar. Interestingly, fruit set in one of the three cultivars examined did not decrease with increasing distance. A similar pattern of fruit set, which was independent of distance, was reported for a different cultivar by DeGrandiHoffman et al. (1984). Using a pigment polymorphism as a marker for one apple cultivar ('Baskatong'), Wertheim (1991) found that pollination from the marked pollen donor was low and inconsistent across years. Seeds sired by the pollen donor most often occurred within $5 \mathrm{~m}$ of the tree but as far away as $40 \mathrm{~m}$. These results are comparable to ours, despite different orchard conditions, in that pollen distances are limited and, within the range of pollen dispersal, siring success was affected by factors in addition to distance.

The maximum (86 $\mathrm{m}$ and $73.5 \mathrm{~m}$, Farmer Jack's Orchard and Dwarf Tree Orchard, respectively) and mean $(15.8 \mathrm{~m}$ and $30.4 \mathrm{~m}$, Farmer Jack's Orchard and Dwarf Tree Orchard, respectively) pollen dispersal distances in our study were considerably farther than the distance most bees move in an orchard. Our observations of pollinators, as well as those of others, confirm that the majority of flights are between flowers on the same tree and secondarily between adjacent trees in the same row or between adjacent rows (Free, 1966; Free and Spencer-Booth, 1964). Moreover, gene dispersal distances often were irregular and not consistently skewed as expected. This dispersal pattern suggests that pollinator flight distances are not a reliable measure of pollen dispersal.

Indirect measures of distance based on pollinator flights often underestimate the actual gene dispersion because indirect measures of pollen movement do not take into consideration the genetic relationships among parents that might influence fertilization success or the extent to which pollinators carry over pollen for many successive visits (Broyles and Wyatt, 1991; Levin, 1981; Schaal, 1980). Honeybees, the predominant insect visitors in the two orchards studied, behave in ways that may also 
Table 4. Fruit set (\%), average number of seeds per fruit and seed number per flower pollinated (fruit set $\times$ seed number per fruit) for five apple cultivars after hand pollinations with 'Idared' pollen. All values are untransformed cultivar means and SE of the means; however, tests of cultivar differences with respect to fruit set were performed on arcsin-transformed data.

\begin{tabular}{|c|c|c|c|c|c|c|}
\hline \multirow[b]{2}{*}{ Cultivar } & \multicolumn{2}{|c|}{ Fruit set $(\%)$} & \multicolumn{2}{|c|}{ Seed/fruit } & \multicolumn{2}{|c|}{ Seed/flower pollinated } \\
\hline & Mean & SE & Mean & SE & Mean & SE \\
\hline 'McIntosh' & $38.0 \mathrm{a}^{\mathrm{z}}$ & 7.1 & $8.6 \mathrm{a}$ & 0.33 & $3.2 \mathrm{a}$ & 0.62 \\
\hline 'Northern Spy' & $34.6 \mathrm{a}$ & 8.1 & $12.2 \mathrm{c}$ & 0.72 & $4.1 \mathrm{a}$ & 0.97 \\
\hline 'Mutsu' & $25.0 \mathrm{ab}$ & 10.2 & $3.2 \mathrm{~b}$ & 0.85 & $0.9 \mathrm{~b}$ & 0.43 \\
\hline 'Empire' & $7.7 \mathrm{bc}$ & 3.4 & $8.6 \mathrm{a}$ & 0.63 & $0.7 \mathrm{~b}$ & 0.31 \\
\hline 'Delicious' & $1.3 \mathrm{c}$ & 1.3 & $7.0 \mathrm{a}-\mathrm{c}$ & --- & $0.1 \mathrm{~b}$ & --- \\
\hline
\end{tabular}

${ }^{\mathrm{z}}$ Mean separations by Tukey-Kramer HSD test $(P=0.05)$.

Table 5. Multiple regression of the dependent variable, percentage of 'Idared' siring success, against four independent variables: 1) minimum distance to pollen donor ('Idared') tree; 2) weighted flowering overlap; 3) cross-compatability; and 4) orchard. $R^{2}=0.73$.

\begin{tabular}{lcccrr}
\hline \hline $\begin{array}{l}\text { Source of } \\
\text { variation }\end{array}$ & df & $\begin{array}{c}\text { Sums of } \\
\text { squares }\end{array}$ & $\begin{array}{c}\text { Variation } \\
\text { explained (\%) }\end{array}$ & F ratio & $P$ value \\
\hline Minimum distance & 1 & 2.51 & 70 & 105.60 & $<0.0001$ \\
Cross-compatability & 1 & 0.08 & 2 & 3.43 & 0.0700 \\
Flowering overlap (wt) & 1 & 0.90 & 25 & 37.72 & $<0.0001$ \\
Orchard & 1 & 0.08 & 2 & 3.45 & 0.0693 \\
\hline
\end{tabular}

contribute to a weak relationship between realized pollen dispersal and pollinator foraging patterns, and to the irregular decline of siring success with distance. They are viewed as inefficient pollinators of apples and, importantly, have been found to disperse pollen through inhive pollen transfer, in addition to transfer from tree to tree. This behavior will tend to broaden the dispersal distances and may even obscure the effects of distance in some cases (DeGrandiHoffman et al., 1986). Unfortunately, our study was not designed to quantify the importance of within-hive pollen transfer.

Consistent with studies of pollen flow in apples and other plants, our research showed that, in addition to distance, the interaction between pollenizer and pollen-recipient may have a large influence on fertilization success (Devlin et al., 1992). Although such an interaction may encompass many ecological and genetic factors, we examined the importance of two: flowering overlap and genetic compatibility. We found that among the cultivars used in our study, there was significant variation in genetic compatibility, but that this was not positively correlated with variation in 'Idared' siring success as we expected. Cross compatibility was negatively correlated with siring success at Dwarf Tree orchard; however, this result may be associated with sampling error as this association was absent in the more comprehensive analysis of the two orchards combined (Table 5). The absence of a relationship between cultivar compatibility and siring success suggests that differences in genetic compatibility are either too small to be detected or interactions between pollen recipient cultivars and pollenizer cultivars cannot be predicted from conventional measures of genetic compatibility, based on single-donor pollinations.

In contrast, flowering overlap explained a significant amount of the variation in siring success among cultivars (Table 5). As expected, the greater the flowering overlap (weighted by overlap in neighboring cultivars), the higher the siring success of the pollenizer. Such a result explains in part why siring success is not a simple function of distance. For example, when two early-flowering cultivars, which are widely separated, begin to flower, there will be no compatible pollen available from the intervening rows. This may temporarily encourage bees to fly greater distances between trees than they otherwise would and result in an increase in pollen donation to a distant variety. It is also important to note that siring success could be predicted not from the degree of overlap between pollen donor and recipient cultivar alone but only when flowering overlap among all neighboring and potentially competing cultivars were considered simultaneously (weighted phenological overlap). This suggests that there is competition among pollen donors for ovules and that the siring success of any given pollenizer will depend on the composition of the entire pollination neighborhood.

Implications for apple orchard design. One of the most important considerations when designing an apple orchard is pollination. In particular, the kinds and spatial arrangement of cultivars in an orchard should be chosen with the goal being to maximize the availability of compatible pollen to all blossoms (king blossoms especially), while simultaneously minimizing the costs for maintenance and harvesting (Dale et al., 1992; Soltész, 1997). Our results support the premise that pollen dispersal is limited within orchards and that distance from a potential pollen donor should be an important criterion dictating the arrangement of apple cultivars. In fact, our data show that siring success of a pollenizer cultivar will decline rapidly beyond three rows $(14.5 \mathrm{~m})$, after which pollen availability becomes less predictable (Fig. 2). This result is consistent with previous recommendations by horticulturists that, for adequate pollination, any given cultivar should be separated by no more than $25 \mathrm{~m}$ (Soltész, 1997) or $30 \mathrm{~m}$ (Dale et al., 1992) from the nearest potential pollenizer cultivar. For a typical high-density orchard, these recommendations mean that no more than four rows of any single cultivar should be planted together, without being intermixed with a row of a pollen donor cultivar.

For both orchards that we examined, there was remarkably little variation in pollen dispersion among the three replicate transects, despite being located at different distances from the bee colonies. In particular, there was no tendency for 'Idared' to sire a higher percentage of seeds or to sire seeds further from the 'Idared' trees in transects that are closer to the hives. This result suggests that pollen dispersion throughout the orchard was not limited by the availability or the location of bees in the orchard. Both of these orchards, however, had strong hives, and patterns of pollen dispersal may be more pollinator limited in orchards with fewer bees. While we were not aware of any additional honeybee colonies, feral or otherwise, near the study orchards, we did observe a moderate number of wild bees at Dwarf Tree Orchard. The presence of these bees may have contributed to the lack of any effect of distance to the honeybee colonies in this orchard. In general, future studies are required to determine the effect of colony strength and role of feral or wild bees on pollen dispersal in apple orchards.

Collectively, our results have important implications for the placement of specific pollenizer cultivars in orchards. Our results indicate that the choice of pollenizers should be based more on degree of flowering overlap than on subtle differences in genetic compatibility, assuming that all cultivars being considered exhibit a basic level of compatibility. Conventional recommendations already advocate that flowering time be considered when choosing cultivars and pollenizers for an orchard (Dale et al., 1992). Specifically, pollination is most effective when pollenizer cultivars adequately cover the period of bloom in the fruit-bearing cultivars. Our results also show that, while most pollination occurs between adjacent rows, the pollenizer cultivar sired as many as $76 \%$ but as few as $23 \%$ of the ovules in a neighboring row (Fig. 2), despite the excessive amount of pollen it produces. This indicates that proximity is no guarantee that pollen from a pollenizer cultivar will successfully sire most of the ovules. This could be due, in part, to the deposition of much pollen on flowers of the pollenizer cultivar itself, which represents wasted pollen and is obviously a concern if pollination efficiency is to be maximized. Limits on siring success of designated pollenizers may also be limited by competition with other potential pollenizer cultivars in the vicinity. This is confirmed by the fact that, in our study, siring success could only be understood with the knowledge of cultivar composition and flowering overlap of apples within a 20-row radius. While the exact size area may vary among orchards, we suggest that the concept of such a "pollination neighborhood" may be a valuable tool for 
designing orchards that can guide decisions regarding composition and flowering overlap of neighboring cultivars.

This study provides one of the first applications of molecular markers to the study of pollen dispersal in apple orchards. In doing so, it provides quantitative insights into pollen dispersal and its ecological and genetic determinants. What, then, is the benefit of this approach to apple growers, especially when most orchard trees already produce an excess of fruit? Attaining sufficient fruit set is important, but that in itself cannot guarantee that pollination is efficient (high number of ovules fertilized per bee employed) nor that the apples are of maximum quality (apple size and shape) (Brault and de Oliveira, 1995). Maximizing efficiency and quality can only be achieved with knowledge about how effectively pollen is dispersed to compatible trees (rather than wasted on incompatible pollinations), how many pollenizer cultivars do and should contribute to single apples, how far pollen is dispersed, and what determines fertilization success in an orchard context (i.e., cultivar arrangement, tree density, cultivar diversity). Molecular markers can contribute much to these questions.

\section{Literature Cited}

Brault, A-M. and D. de Oliveira. 1995. Seed number and an asymmetry index of 'McIntosh' apples. HortScience 30:44-46.

Broyles, S.B. and R. Wyatt. 1991. Effective pollen dispersal in a natural population of Asclepias exaltata: The influence of pollinator behavior, genetic similarity, and mating success. Amer. Naturalist 138:1239-1249.

Charlesworth, D. and B. Charlesworth. 1981. Allocation of resources to male and female functions in hermaphrodites. Biol. J. Linnean Soc. 15:5774.

Charnov, E.L. 1982. The theory of sex allocation. Princeton Univ. Press, Princeton, N.J.

Dale, A., D.C. Elfving, K.H. Fisher, N.W. Miles, G. Tehrani, and K.R. Wilson. 1992. Fruit cultivars: A guide to commercial growers. Ontario Ministry of Agriculture and Food.
DeGrandi-Hoffman, G., R. Hoopingarner, and K. Lomparens. 1986. Influence of honey bee (Hymenoptera: Apidae) in-hive pollen transfer on cross-pollination and fruit set in apple. Environ. Entomol. 15:723-725.

DeGrandi-Hoffman, G., R. Hoopingarner, and K. Baker. 1984. Pollen transfer in apple orchards: Tree-to-tree or bee-to-bee. Bee World 65:126133.

Devlin, B., J. Clegg, and N.C. Ellstrand. 1992. The effects of flower production on male reproductive success in wild radish populations. Evolution 46:1030-1042.

Eckert, C.G. and S.C.H. Barrett. 1994. Inbreeding depression in partially self-fertilizing Decodon verticillatus (Lythraceae): Population genetic and experimental analyses. Evolution 48:952-964.

Free, J.B. 1962. The effect of distance from pollinizer cultivars on the fruit set on trees in plum and apple orchards. J. Hort. Sci. 37:262-271.

Free, J.B. 1966. The foraging areas of honeybees in an orchard of standard apple trees. J. Appl. Ecol. 3:261-268.

Free, J.B. 1993. Insect pollination of crops. 2nd ed. Academic, San Diego.

Free, J.B. and Y. Spencer-Booth. 1964. The effect of distance from pollinizer cultivars on the fruit set of apple, pear and sweet-cherry trees. J. Hort. Sci. 39:54-60.

Gunst, R.F. and R.L. Mason. 1980. Regression Analysis and its application: A data-oriented approach. Marcel Dekker, New York.

Harder, L.D. and J.D. Thomson. 1989. Evolutionary options for maximizing pollen dispersal of animal-pollinated plants. Amer. Naturalist 133:323344.

Hebert, P.D.N. and M.J. Beaton. 1989. Methodologies for allozyme analysis using cellulose acetate electrophoresis: A practical handbook. Helena Lab., Beaumont, Texas.

Holm, S. 1979. A simple sequentially rejective multiple test procedure. Scandinavian J. Stat. 6:65-70

Janick, J., J.N. Cummins, S.K. Brown, and M. Hemmat. 1996. Apples, p. 1-77. In: J. Janick and J.N. Moore (eds.). Fruit breeding, Vol. I. Tree and tropical fruits. Wiley, New York.

Kron, P., B.C. Husband, and P.G. Kevan. 2001. Across- and along-row pollen dispersal in high-density apple orchards: Insights from allozyme markers. J. Hort. Sci. and Biotechnology 76:286-294.
Lateur, M. 1996. The intercompatibility of old apple cultivars selected for partial disease resistance, and their use as pollenizers. Acta Hort. 423:151159.

Levin, D.A. 1981. Dispersal versus gene flow in plants. Ann. Missouri Bot. Garden 68:233-253.

Levin, D.A. and H.W. Kerster. 1974. Gene flow in seed plants. Evolutionary Biol. 7:139-220.

Maggs, D.H., G.J. Martin, and R.A. Needs. 1971 The spread of cross-pollination in a solid block of 'Granny Smith' apples. Australian J. Exp. Agr. Animal Husbandry. 11:113-117.

Manchenko, G.P. 1994. Handbook of detection of enzymes on electrophoretic gels. CRC Press, Boca Raton, Fla.

Mayer, D.F., C.A. Johansen, and D.M. Burgett. 1986. Bee pollination of tree fruits. Washington State Univ.-Pacific Northwest Coop. Ext. Publ. PNW0282.

Milutinovic, M., G. Surlan-Momirovic, and D. Nikolic. 1995. Relationship between pollinizer distance and fruit set in apple. Acta Hort. 423:9194.

Rice, W.R. 1989. Analyzing tables of statistical tests. Evolution 43:223-225.

Schaal, B. 1980. Measurement of gene flow in Lupinus texensis. Nature 284:450-451.

Sokal, R.R. and F.J. Rohlf. 1981. Biometry, 2nd ed. Freeman and Co., San Francisco.

Soltész, M. 1997. The location of cultivars in apple orchards. Acta Hort. 437:441-443.

Weeden, N.F. and R.C. Lamb. 1985. Identification of apple cultivars by isozyme phenotypes. J. Amer. Soc. Hort. Sci. 110:509-515.

Weeden, N.F. and R.C. Lamb. 1987. Genetics and linkage analysis of 19 isoyzmes in apple. J. Amer. Soc. Hort. Sci. 112:865-872.

Wertheim, S.J. 1991. Malus cv. Baskatong as an indicator of pollen spread in intensive apple orchards. J. Hort. Sci. 66:635-642.

Wertheim, S.J. 1996. Methods for cross pollination and flowering assessment and their interpretation. Acta Hort. 423:237-241.

Willson, M.F. 1979. Sexual selection in plants. Amer. Naturalist 113:777-790.

Wilson, K.R. 1990. Apple Rootstocks. Ontario Ministry of Agriculture and Food Factsheet 90-118.

Wright, S. 1978. Evolution and the genetics of populations. Vol.4. Variability within and among natural populations. Univ. of Chicago Press, Chicago. 